\title{
Review of Chionelasmus darwini (Pilsbry, 1907) (Cirripedia: Balanomorpha): A Comparison between the Pacific and Indian Ocean Populations
}

\author{
Toshiyuki Yamaguchi \\ Department of Earth Sciences, Chiba University, 1-33 Yayoi-cho, Inage, Chiba 263-8522. Japan
}

(Received 24 February 1997; Accepted 10 November 1997)

\begin{abstract}
Chionelasmus darwini (Pilsbry, 1907) was first collected at 417 to $430 \mathrm{~m}$ depth near Kauai, Hawaiian Islands. Pilsbry (1911) subsequently recognized that it was distinct from Catophragmus s.s. and proposed the subgenus Chionelasmus to accommodate it. Nilsson-Cantell (1928) elevated Chionelasmus to full generic rank based on a complete specimen collected from 526m depth off Port Mathurin, Rodrigues Island in the western Indian Ocean, largely because the wall turned out to be composed of six rather than eight plates. These two specimens plus 11 specimens from the Hawaiian Islands and three specimens from Madagascar contained in the Benthic Invertebrate Collection of Scripps Institution of Oceanography, and one from the Kermadec Islands of the South Pacific (Foster 1981), were utilized in the present study. The morphology of the scutum and tergum and the ontogenetic development of the third and fourth whorls of basal imbricating plates in the Pacific and Indian Ocean populations are different, and therefore a new subspecies, Chionelasmus darwini cantelli, is proposed for the latter.

Key Words: Cirripedia, Chionelasmus darwini, Hawaii, Indian Ocean, new subspecies, geographic variability, imbricating plates.
\end{abstract}

\section{Introduction}

Chionelasmus darwini was described by Pilsbry (1907) as Catophragmus darwini based on incomplete spccimens from 417 to $430 \mathrm{~m}$ depth near Kauai, Hawaiian Islands [Albatross station 3998 (type hard parts, USNM cat. no. 32407; type soft parts, USNM 32408)]. However, the type turns out not be a single specimen. While Pilsbry (1907) could only account for six plates in his fragmentary material, he believed that the intact wall would have been composed of cight: the rostrum (R); paired rostro-latera $(R L)$, latera $(\mathrm{L})$, and carino-latera $(\mathrm{CL})$; and the carina $(\mathrm{C})$. The wall, which supports the operculum (paired scuta and terga), was surrounded by some whorls of basal imbricating plates.

Nilsson-Cantell (1928) redescribed Chionelasmus darwini based on a complete specimen [Natural History Museum, London, reg. no. 1928.5.23.84] collected from a telegraph cable off Rodrigues Island in the western Indian Ocean at $526 \mathrm{~m}, 15.3 \mathrm{~km}$ north and $64.4 \mathrm{~km}$ west of Port Mathurin. Contrary to Pilsbry's (1907) expectation, Nilsson-Cantell (1928) found that the primary wall consisted of six rather than eight plates. Newman (1987) proposed a new system for tracing the ontogeny of the imbricating and parietal plates of Chionelasmus darwini in order to clarify which plates are present in Catophragmus but lacking in Chionelasmus.

Yamaguchi and Newman (1990) described Eochionelasmus ohtai from the 
deep-sea abyssal hydrothermal field in the North Fiji Basin (NFB) at 1990m depth. Based on an analysis of the organization of the imbricating plates and a reinterpretation of the homology of the so-called L/CL plate of Newman (1987), the new species was determined to be not only more generalized than its closest relative, Chionelasmus darwini, but to be the most primitive living balanomorph barnacle. Subsequently, additional specimens of $E$. ohtai were collected from the abyssal hydrothermal fields in the North Fiji Basin, as well as from new populations in the Lau Basin (south of Tonga) and the Manus Basin (north of Papua New Guinea) (Yamaguchi and Newman 1997b).

$\Lambda$ new species of Eochionelasmus based on a few small specimens from near Easter Island on the East Pacific Rise was also recognized (Yamaguchi and Newman 1997a).

These two species of Eochionelasmus, one from three back-arc basins in the West Pacific and one from a mid-oceanic ridge along the East Pacific Rise, display differences in the ontogenetic development of the basal imbricating plates and also in the shape of the wall and the opercular parts. Likewise, the ontogenetic development of the basal imbricating plates and the morphology of the opercular valves distinguish the Hawaiian population of Chionelasmus darwini from that in the western Indian Ocean. Therefore, a new subspecies, Chionelasmus darwini cantelli, is proposed for the Indian Ocean population.

\section{Analysis of the Type Material of Chionelasmus darwini Contained in the U. S. National Museum of Natural History}

Pilsbry (1907: plate 5) presented eight figures of the wall and the opercular plates of Chionelasmus darwini; fig. 1 includes the articulated left scutum (S) and tergum (T), and the left carinolatus (CL) and carina (C); fig. 2 the articulated rostrum (R) and right rostrolatus (RL), and four basal imbricating plates $\left(r^{1}, r^{2}, r l\right.$, $\mathrm{r}^{2}$ ); and figs 3-8 represent a carina, right scutum (interior), rostrum, left tergum, right scutum, and left tergum (interior), respectively. Pilsbry (1907: 190) mentioned, "Fragments of two or three individuals were taken, the largest and most perfect being drawn in plate $\mathrm{v}$, figures 1 and 2 , in which the following plates are preserved in place: Carina, carino-lateral, terga, scuta; and in another individual the rostrum, rostro-lateral and four plates of the third whorl." And he added, "Figures 3 (top view of carina) and 5 (anterior view of rostrum) represent detached valves of another individual or individuals." Thus, he knew that the plates illustrated two or three individuals, and he concluded that the parts in fig. 1 did not belong to the same individual as those in fig. 2. He did not explain this conclusion, but it was likely because he thought he had a species of Catophragmus, which has eight rather than six primary plates making up the wall. Pilsbry (1907) designated unspecified hard and soft parts as the type of Calophragmus darwini under the catalogue numbers USNM 32407 and USNM 32408, respectively.

I had the opportunity to observe the typc materials of what is now known as Chionelasmus darwini at the U.S. National Museum of Natural History in 1989. The hard parts included six primary plates (two carinae, one carinolatus, one rostrolatus, and two rostra), and four basal imbricating plates, but I observed that the carina and carinolatus of Pilsbry's fig. 1 had become disarticulated from the left scutum and 
tergum (the left scutum and tergum were missing), and that the rostrum of his fig. 2 had become disarticulated from the rostrolatus and from the four basal imbricating plates. As the left tergum of fig. 1 is misplaced, I couldn't confirm whether or not it was the same plate as the left tergum of lig. 6. I would like to have seen Pilsbry's material again in connection with my present research on the Hawaiian and Indian Ocean populations of Chionelasmus darwini, but unfortunately it has been misplaced (J. Clark-Walker, pers. comm.). Therefore I must rely on Pilsbry's (1907) description and illustrations and my 1989 observations and drawings, in selecting the lectotype specimen of Chionelasmus darwini from Pilsbry's type lot. Pilsbry (1907:190) mentioned that the carina of fig. 3 and rostrum of fig. 5 were not the same as the carina of fig. 1 and the rostrum of fig. 2, and with this I agree. However, Pilsbry was apparently incorrect in thinking that the hard parts in his figs 1 and 2 represented two individuals. Knowing now that the species is six- rather than eight-plated allows one to determine that these two sets of plates came from the same individual.

In Chionelasmus darwini the margin of the alae of the carinolatus articulates with that of rostrum, but the suture is not visible from outside because it is covered by the rostrolatus. Unlike the situation in Catophragmus, the rostrolatus does not enter into the sheath between rostrum and the adjacent plate, the carinolatus. It is very important to confirm that the carinolatus of Pilsbry's fig. 1 articulates properly with the rostrum of fig. 2 rather than the rostrum of fig. 5 . During my visit in 1989, the articular margin of the rostrum in fig. 2 could be observed from inside and I drew the inner side of both rostra. Although the rostrum of fig. 2 was disarticulated from the rostrolatus and the imbricating plates, it was easy to identify it. It is almost as high but wider than the rostrum in fig. 5. A comparison of the lengths of the articular margins of these rostra with that of the carinolatus in fig. 1 shows that they are almost the same. However, the distance of the lower sutural margin from the base is virtually the same in the rostrum of fig. 2 and the carinolatus of fig. 1 . Therefore, it is highly likely that hard parts of fig. 1 belong to the same individual as those of fig. 2. The next question is: to which of the individuals included in Pilsbry's plate 5 do the soft parts (USNM cat. no. 32408) belong? I observed six pairs of cirri, the caudal appendages, one mandible, and two first maxillae; the labrum and second maxillae were not illustrated by Pilsbry (1907) and I did not find them in 1989.

In sum, the type designated by Pilsbry (1907), USNM cat. nos. 32407 and 32408, must be interpreted as a syntype series. I would like to designate as lectotype the individual illustrated in figs 1 and 2 of Pilsbry's (1907) pl. 5 and figs 4A-D in his text. The remaining shell plates, illustrated in figs $3-8$ of pl. 5 , comprise one or more incomplete paralectotypes. It remains unclear whether the soft parts belong to the lectotype or another individual.

\section{Material Examined}

In this study, I compared: la-f) eleven specimens from five localities in the Hawaiian Islands, 2) three specimens from off Madagascar contained in the Benthic Invertebrate Collection of Scripps Institution of Oceanography (SIO), 3) the holotype of the new subspecies, Nilsson-Cantell's (1928) specimen from off Rodrigues Island, Indian Ocean, deposited in the Natural Ilistory Museum, London, and 4) Foster's (1981) specimen from the Kermadec Islands. 
1a) USNM 32407: Syntype lot of Chionelasmus darwini (Pilsbry, 1907:188), incomplete specimens, Albatross St. 3998, from Kauai, Hawaii, 417-430m; specimens now missing.

1b) SIO C6207 A-D: R/V Te Vega Exped., St. 23-95, south of Molokai, Hawaii, on alcyonarian "gold coral" (see Newman and Ross 1976: frontispiece). Four specimens.

1c) SIO C6224A-B: Sango III, Haul 1, Makapuu, Oahu, Hawaii, 420m, on bamboo coral Ceralosis grandis (Nutting), $8-10^{\circ} \mathrm{C}$, Coll: R. Grigg. Two specimens.

1d) SIO C6235: St. 4-7, Molokai, Hawaii. One specimen.

1e) SIO C6236A-B: St. 0033, Nihoa Bank, Hawaii, $23^{\circ} 15.7^{\prime} \mathrm{N}, 162^{\circ} 37.1^{\prime} \mathrm{W}, 207$ 260m, Coll: M. Palmgreen, on Gerardia sp. (see Newman 1987: fig. 6). One specimen.

1f) SIO C7787A-B: off Makapuu Pt., Kaiwi Channel, Oahu, Hawaii, 336-366m, attached to zoanthids, Coll: B. Bartko. Two specimens.

2) SIO C6237A-C: Madagascar, $12^{\circ} 52.0^{\prime} \mathrm{S}, 48^{\circ} 10.3^{\prime} \mathrm{E}, 420-428 \mathrm{~m}$, Coll: A. Crosnier. Three specimens.

3) BMNH reg. no. 1928.5.23.84: $15.3 \mathrm{~km}$ north and $64.4 \mathrm{~km}$ west of Port Mathurin, Rodrigues Island, Indian Ocean, $526 \mathrm{~m}$, on a telegraph cable. Nilsson-Cantell (1928:446, figs 1 \& 2) discovered in this adult hermaphrodite that the species has a wall of six rather than eight plates, and Hui and Moyse (1984: 91, fig. 1) discovered a complemental male attached to it.

4) Foster's (1981: fig. 3) specimen from off the Kermadec Is. (New Zealand Oceanographic Institute St. K858, $30^{\circ} 34^{\prime} \mathrm{S}, 178^{\circ} 23^{\prime} \mathrm{W}, 1180 \mathrm{~m}$ ); now missing (Buckeridge 1997). Buckeridge (1997) described Chionelasmus crosnier inhabiting a living octocoral and closely resembling Chionelasmus darwini, from a guyot on Norfolk Ridge, south of New Caledonia. The new species has same shell arrangement of the parietal wall and the whorls of basal imbricating plates as Chionelasmus darwini (mentioned below), but is distinguished from that species by the opercular valves and soft parts (Buckeridge 1997). Buckeridge (1997) thinks Foster's (1981) specimen is a juvenile of Chionelasmus crosnier.

\section{Morphological Comparison between the Hawaiian and Indian Ocean Populations}

Size (Table 1, Fig. 1):

The rostro-carinal (R-C) and carino-lateral (CL) diameters of specimens from the Indian Ocean are larger than $12 \mathrm{~mm}$ and $11 \mathrm{~mm}$, respectively. Specimens from the Hawaiian population are smaller, having R-C and CL diameters of $11 \mathrm{~mm}$ and $9 \mathrm{~mm}$, respectively (Fig. 1).

\section{Opercular Valves (Fig. 2):}

The Pacific population differs from the Indian Ocean population in the articular ridge of the scutum being prominent and wide rather than relatively inconspicuous and narrow, and the articular furrow being narrow rather than wide. Furthermore, the basiscutal angle of the tergum is angular rather than rounded. The morphological characters of the opercular valves of recent specimens from the Hawaiian population are not only the same as those of the Hawaiian type lot, but they are also the same as those from the Kermadec Islands, north of New Zealand (Foster 1981). They are unlike Nilsson-Cantell's (1928) specimen from off Rodrigues I. and the specimens from Madagascar. 
Table 1. Sizes of examined specimens of Chionelasmus darvini

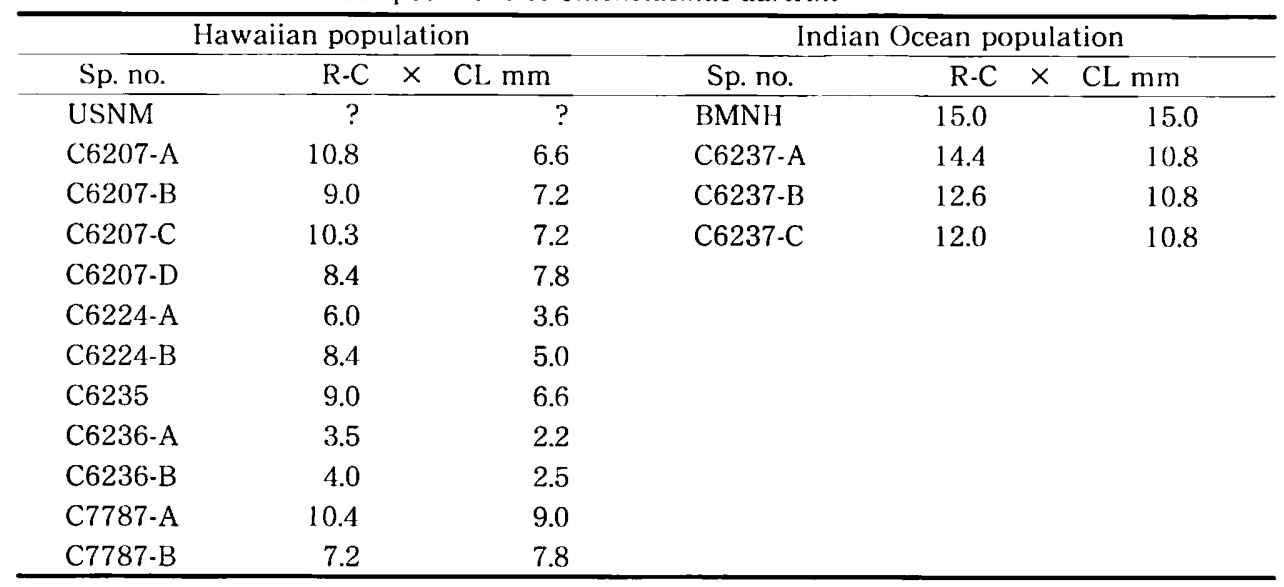



Fig. 1. Size comparison between the Hawaiian and Indian Ocean populations. Rostrum-carina $(\mathrm{R}-\mathrm{C})$ and carinolatera $(\mathrm{CL})$ diameters, in $\mathrm{mm}$. 

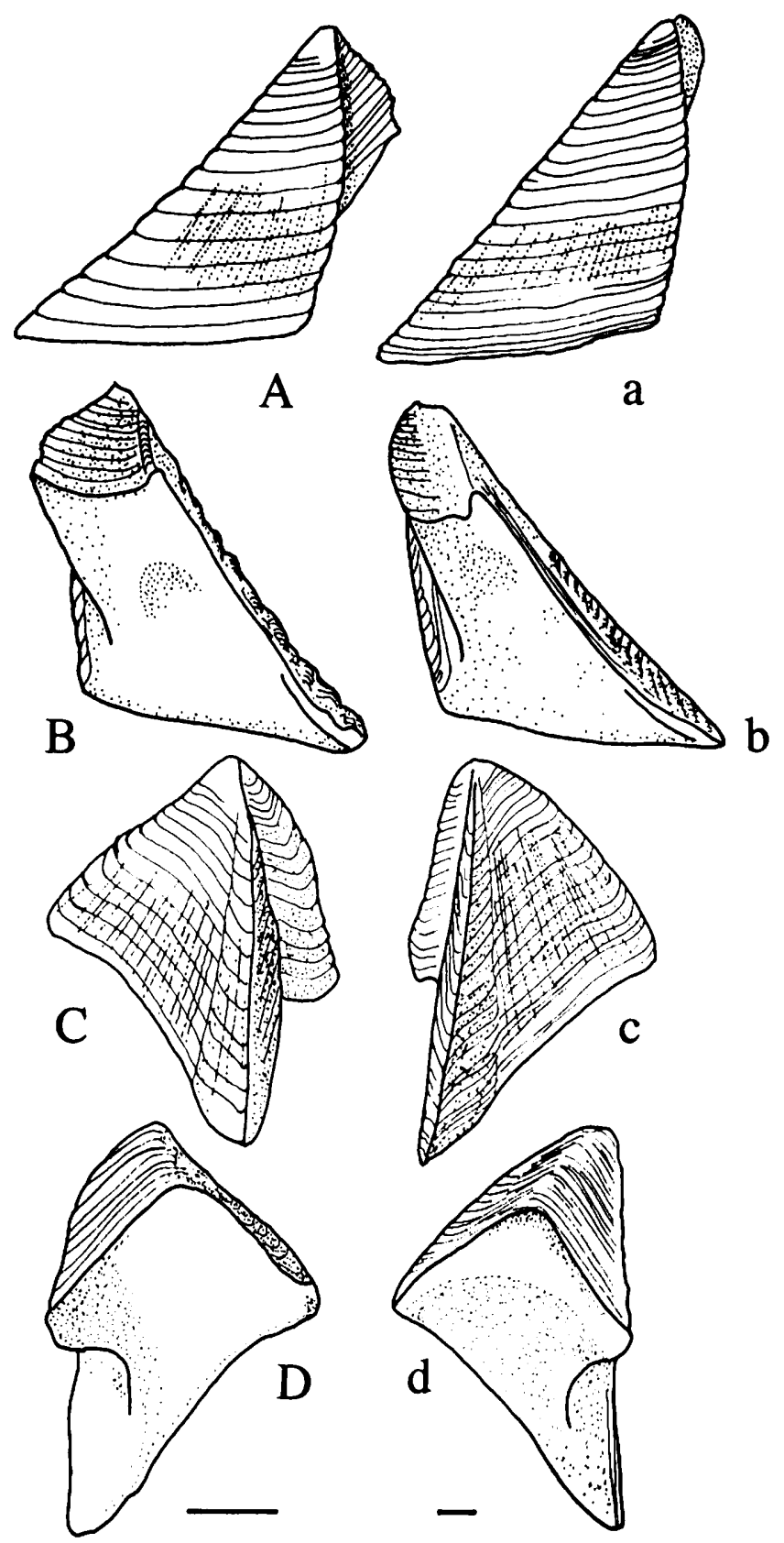

Fig. 2. A-D, scuta and terga of type lot (USNM 32407) of Hawaiian Chionelasmus darwini darwini; a-d holotype (BMNH 1928.5.23.84) of western Indian Ocean Chionelasmus darwini cantelli subsp. nov. A, B, exterior and interior views of right scutum; C, D, exterior and interior views of left tergum; a, b, exterior and interior views of right scutum; c, d, exterior and interior views of right tergum. Scale bar $=1 \mathrm{~mm}$. 
Chionelasmus darwini darwini Pilsbry

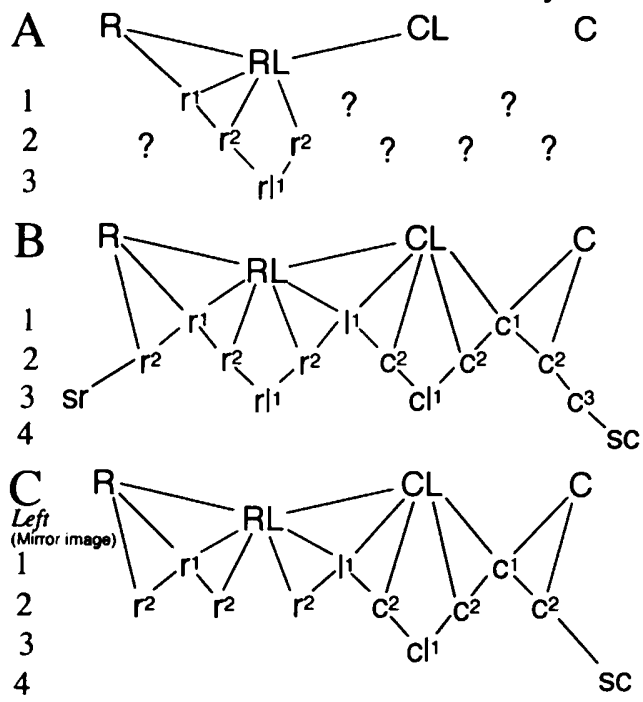

Chionelasmus darwini cantelli subsp. nov.

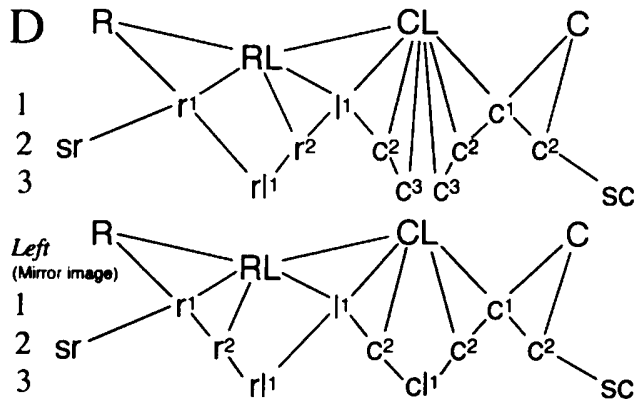

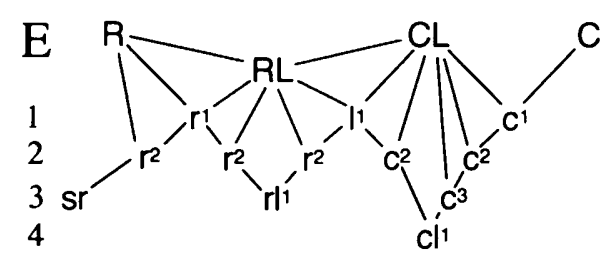

Fig. 3. Arrangement of the wall plates in the Ilawaiian population of Chionclasmus darwini darwini (A-C) and the western Indian Ocean population of Chionelasmus darwini cantelli subsp. nov. (D and E) from right side unless indicated otherwise. A, type lot (USNM 32407) of Chionelasmus darwini darwini; B, SIO C6207B from south of Molokai (Newman and Ross, 1976. frontispiece); C, SIO C7787B from off Oahu; D, Nilsson-Cantell's (1928) specimen (BMNH 1928.5.23.84) from Rodrigues Is., holotype of Chionelasmus darvini cantelli subsp. nov.; E, SIO C6237C from off Madagascar. Parietal plates: R, rostrum; C, carina; RL, rostrolatus; CL, carinolatus. Basal imbricating plates: $r$, imbricating plates added between $\mathrm{R}$ and $\mathrm{I}^{\prime}$; $c$, imbricating plates added between $\mathrm{l}^{\prime}$ and $\mathrm{C} ; \mathrm{sr}$ and sc, imbricating plates added directly below $\mathrm{R}$ and $\mathrm{C} ; \mathrm{rl}^{\prime}$ and $\mathrm{Cl}^{\prime}$, imbricating plates added directly below RL and CL. 
The Imbricating Plates (Figs 3-6):

Nine individuals from Hawaii (exclusive of the type lot) and four individuals from the Indian Ocean (including Nilsson-Cantell's specimen) were examined to determine the order of ontogenetic appearance of the basal imbricating plates (Figs 3,5 ). The type lot could not be used in this analysis because of the fragmented condition of the specimens. In the more recent Hawaiian individuals, the arrangement of the plates could be determined in nine individuals up to the second whorl, in eight up to the third whorl, and in four up to the fourth whorl. As for the Indian Ocean individuals, the arrangement could be determined in four specimens up to the second and third whorls and in one individual up to the fourth whorl.

The arrangements of the right and left sides of each whorl are shown and compared in Figs 3-5. There is little difference between the right and left sides of single individuals as well as among individuals. The first whorl of imbricating plates invariably consists of $\mathrm{r}^{\mathrm{l}}, \mathrm{l}^{1}$, and $\mathrm{c}^{1}$ in both the Hawaiian and Indian Ocean populations (Figs 3-5). However, there are variations in the second and successive whorls both within and between populations. Therefore, a "generalized shell arrangement" was reconstructed for the Pacific and Indian Ocean populations, based on these variations. Only complete specimens were used in determining the generalized arrangement of the imbricating plates in the two populations (Fig. 6).

While the second whorl of basal imbricating plates in the Hawaiian population is generally represented by three pairs of $\mathrm{r}^{2}$ and $\mathrm{c}^{2}$ plates, $\mathrm{sr}, \mathrm{rl}^{1}$, or $\mathrm{cl}^{1}$ plates may also appear there in some specimens (Fig. 4). The incidence of such irregular appearances in the nine individuals was $3 / 9(33 \%)$ for sr, $5 / 9(56 \%)$ for $r^{2}, 7 / 9(78 \%)$ for $r^{2}, 1 / 9$ (11\%) for $\mathrm{rl}^{\prime}, 9 / 9(100 \%)$ for $\mathrm{r}^{2}, 9 / 9(100 \%)$ for $\mathrm{c}^{2}, 2 / 9$ (22\%) for $\mathrm{cl}^{\prime}, 9 / 9$ (100\%) for $\mathrm{c}^{2}$, and $9 / 9(100 \%)$ for $\mathrm{c}^{2}$ (Fig. 4B). The appearance of $\mathrm{sr}$ in the second whorl occurs when the rostral-most of the three pairs of $r^{2}$ fails to appear in the second or subsequent whorls. The third whorl gencrally includes $\mathrm{rl}^{1}, \mathrm{cl}^{1}$, and the carinal-most $\mathrm{c}^{3}$. The frequency of appearances of the basal imbricating plates, from the rostral to the carinal side in eight individuals, is given in Fig. 3C. Tardy $\mathrm{Cl}^{1}$ plates appear in the fourth whorl and sc occurs exclusively in the fourth whorl in the Pacific but not the Indian Ocean population.

In the Indian Ocean population (Fig. 5B), the second whorl of basal imbricating plates also has three pairs each of $r^{2}$ and $c^{2}$ plates, unless sr has appeared precociously. The third whorl includes sr as frequently as the second, and there is a precocious appearance of sc in two of four individuals. As in the Hawaiian population, when $\mathrm{Cl}^{\prime}$ is present, $\mathrm{c}^{3}$ is absent. Thus, the Indian Ocean population not only appears to be larger in size (Fig. 1), but also gains some imbricating plates precociously by the exclusion of others, especially the carinal-most $c^{3}$ (Fig. 5).

\section{Generalized Shell Arrangement:}

Based on the frequency of appearance of imbricating plates during ontogeny, generalized shell arrangements for the Hawaiian and Indian Ocean populations were composed (Fig. 6). In cases of exclusion; e.g. where the precocious appearance of one plate blocks the appearance of another (exclusion of $\mathrm{r}^{2}$ by $\mathrm{sr}$ in the second whorl, or of $\mathrm{c}^{3}$ by $\mathrm{cl}^{1}$ in the third whorl), the frequency of exclusion was used to determine to which whorl a plate generally belonged. In the case of $s r$ and $r^{2}$, the frequencies were $5 / 9(56 \%)$ and $3 / 9(33 \%)$, respectively. Therefore, $r^{2}$ and sr must belong to second and third whorls, respectively. In the case of $\mathrm{cl}^{1}$ and $\mathrm{c}^{3}$, the frequencies were $7 / 8$ 


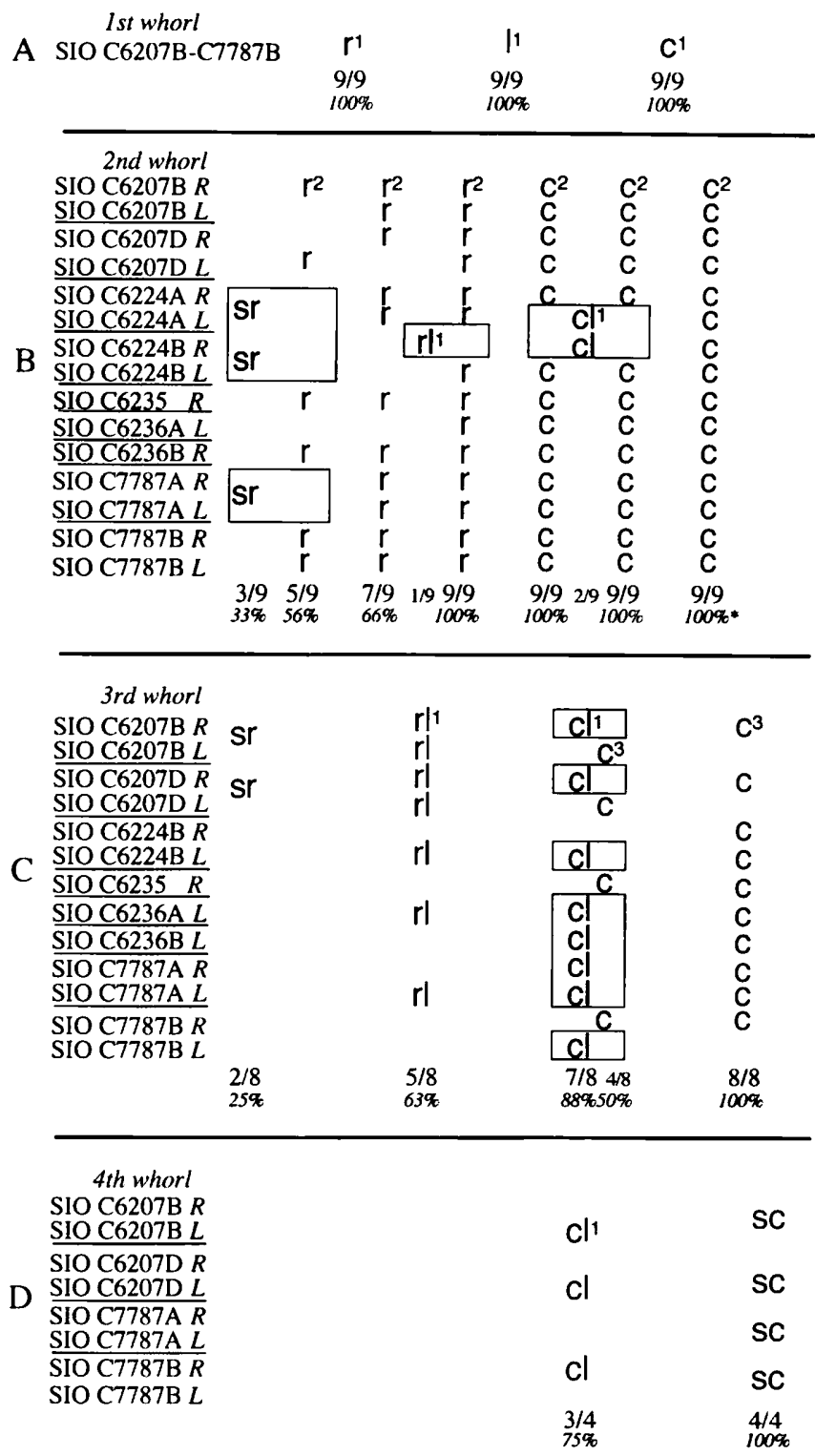

Fig. 4. Shell arrangement of the imbricating plates in each whorl from first (A) to fourth whorl (D) in the Hawaiian population of Chionelasmus darwini darwini, each specimen identified by SIO catalogue number. Symbols as in Fig. 3. $R, L$, right, left; numerator, number of individuals having the particular imbricating plates in the whorl; denominator, number of individuals having the whorl; \%, rate of appearance of each imbricating plate; boxes showing the exclusive relationship between adjacent imbricating plates, apparently largely correlating with precocious development of the following plate; * showing the notable difference in the frequency of appearance of the carinal-most $\mathrm{c}^{2}$ in the second whorl between the Hawaiian and Indian Ocean populations. 
(88\%) and 4/8 (50\%), respectively. Therefore, $\mathrm{cl}^{1}$ and $\mathrm{c}^{3}$ are assigned to the third and second whorls, respectively.

The generalized Hawaiian form consists of, from the rostral to carinal side: sr, $r^{2}, r l, r^{2}, r^{1}, r^{2}, l^{1}, c^{2}, c^{1}, c^{2}, c l, c^{2}, c^{3}$, and sc (Fig. 6A). In this case, sr and sc appear in third and fourth whorls, respectively. The arrangement for the generalized Indian form not only differs in lacking $\mathrm{c}^{3}$, but also in that both $\mathrm{sr}$ and $\mathrm{sc}$ appear in the third whorl (Fig. 6B). Therefore, while no significant difference between the Hawaiian and Indian Ocean populations was found in the second whorl, the precocious appearance of $\mathrm{sc}$ to the exclusion of $\mathrm{c}^{3}$ in the third whorl is notable (Fig. 6B). Furthermore, while the frequencies of appearance of the carinal-most $c^{2}$ in the second whorl and of sr and sc are $100 \%$ in the Hawaiian population, they are only $50 \%$ in the Indian Ocean population (Figs 4 and 5 ).

While imbricating plates $\mathrm{sr}, \mathrm{rl}^{\prime}$, and $\mathrm{cl}^{\prime}$ of Chionelasmus darwini sometimes appear in the second rather than the third whorl, they always appear in the third whorl in Eochionelasmus ohtai (Yamaguchi and Newman 1990) and a soon to be described species of Eochionelasmus (Yamaguchi and Newman 1997a). While Eochionelasmus ohtai has $\mathrm{sr}^{2}, \mathrm{rl}^{2}, \mathrm{cl}^{2}$, and $\mathrm{sc}^{2}$ plates, Chionelasmus darwini has no such imbricating plates in subsequent whorls. This tendency towards precocious appearance of plates and a reduction in the number of plates not only indicates a significant

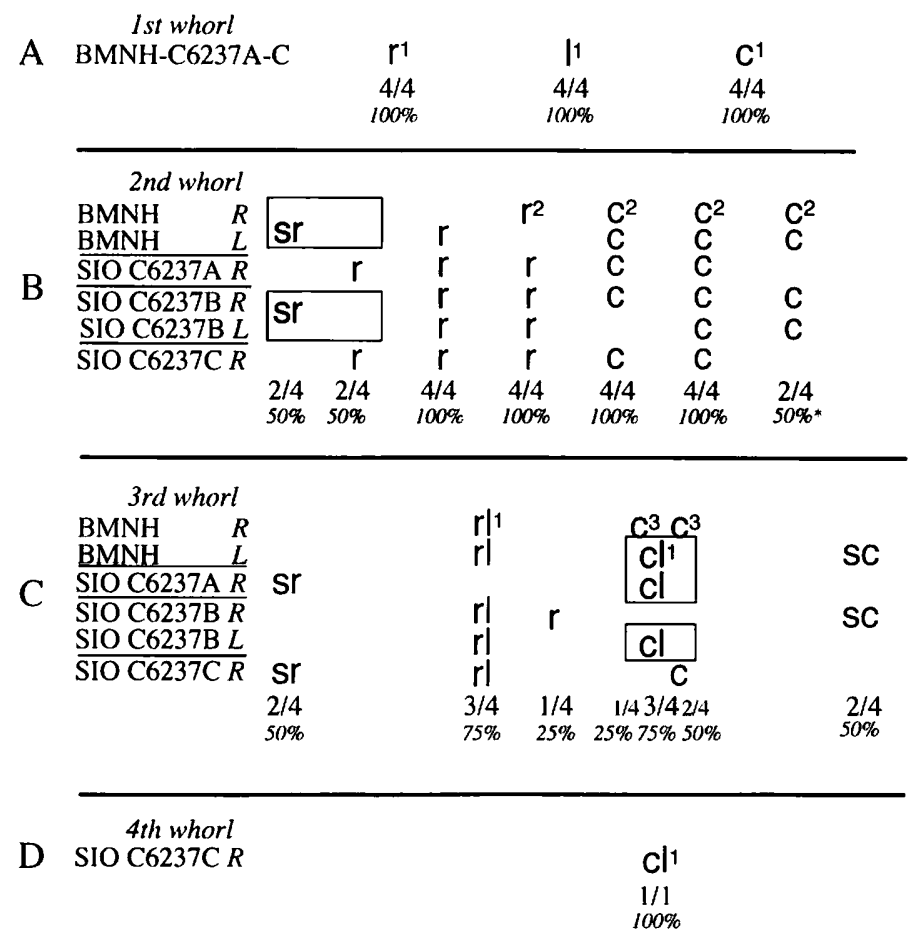

Fig. 5. Shell arrangement of the imbricating plates in each whorl from first (A) to fourth whorl (D) in the Indian Ocean population of Chionelasmus darwini cantelli subsp. nov. Symbols as in Figs 3 and 4. 
divergence between Eochionelasmus and Chionelasmus, but between the Pacific and Western Indian Ocean populations of Chionelasmus.

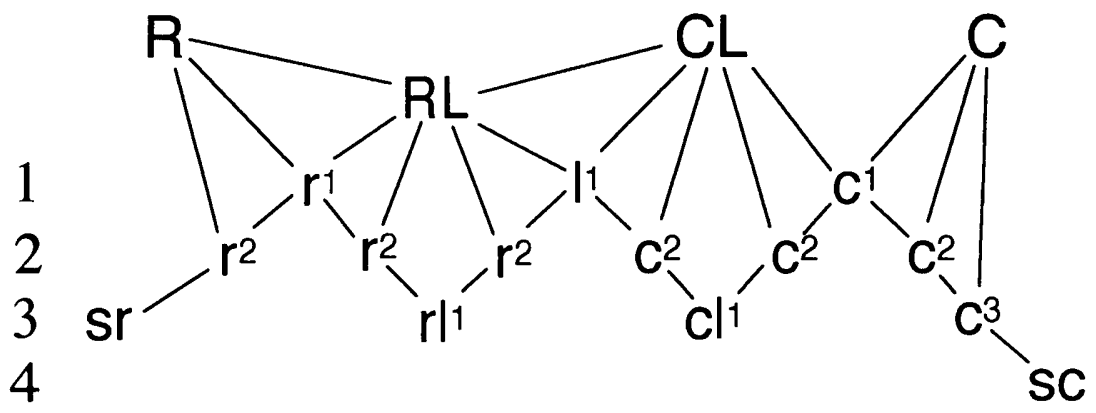

Chionelasmus darwini darwini (Pilsbry)
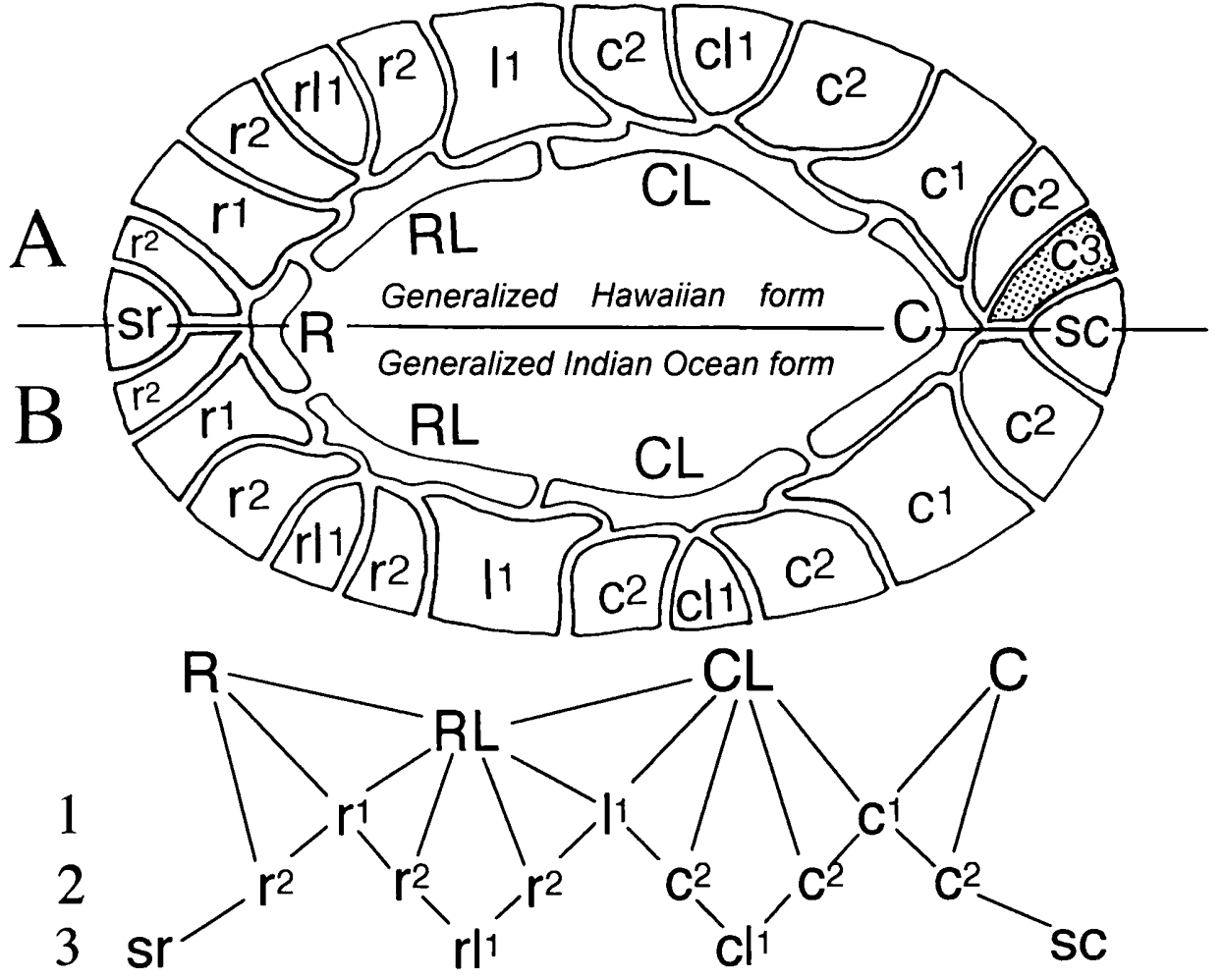

Chionelasmus darwini cantelli subsp. nov.

Fig. 6. The generalized shell arrangement of the parietal wall and the whorls of the basal imbricating plates in Hawaiian Chionelasmus darwini darwini (A, modified from Newman 1987) and in the Indian Ocean Chionelasmus darwini cantelli subsp. nov. (B) Symbols as in Fig. 3. 


\section{Arthropodal Structures:}

Unfortunately, the three individuals from off Madagascar (SIO C6237 A-C) had no soft parts. Therefore, the comparison between the Hawaiian and Indian Ocean populations is based on the descriptions of Pilsbry (1907) and Nilsson-Cantell (1928), as well as that of Hui and Moyse (1984), who discovered and described a male attached to Nilsson-Cantell's Chionelasmus darwini. As mentioned by NilssonCantell (1928), the Indian Ocean population closely resembles the type lot of Chionelasmus darwini from Hawaii. There are no notable differences between descriptions of Pilsbry (1907) and Nilsson-Cantell (1928) in the morphology of the mouthparts, the number of articles in the cirri and caudal appendages, and the form of the branchia of the hermaphrodites (Table 2). Nor does there appear to be any significant difference between the complemental male described by Hui and Moyse (1984) and the one described by Yamaguchi and Newman (1990).

\section{Conclusion}

The opercular valves differ morphologically between the Hawaiian and Indian Ocean populations and this alone would be sufficient to distinguish them. The basal imbricating plates also differ in the ontogenetic appearance of sc in the third rather than the fourth whorl and in the concomitant deletion of $\mathrm{c}^{3}$ in the Indian Ocean population. These morphological differences indicate that substantial divergence has occurred between the two populations, and it is proposed that the Indian Ocean population be recognized as Chionelasmus darwini cantelli subsp. nov.

\section{Systematics}

Subclass Cirripedia Burmeister, 1834

Superorder Thoracica Darwin, 1854

Order Sessilia Lamarck, 1818

Suborder BALANOMORPHA Pilsbry, 1916

Superfamily Chionelasmatoidea Buckeridge, 1983

Family Chionelasmatidae Buckeridge, 1983

Genus CHIONELASMUS Pilsbry, 1911

Chionelasmus darwini darwini (Pilsbry 1907)

Pilsbry 1907: 188, fig. 4, pl. 5, figs 1-8. As Catophragmus darwini; Newman and Ross 1976: frontispiece.

Diagnosis: Basal imbricating plate $\mathrm{c}^{3}$ present and overlapping $\mathrm{sc}$; articular furrow of scutum narrow; articular ridge of tergum wide and prominent; articular ridge of tergum not reaching to basitergal angle; and basiscutal angle pointed rather than rounded, as compared to Chionelasmus darwini cantelli subsp. nov.

Type: The individual shown in Pilsbry's (1907) pl. 5, figs 1 and 2, which has some of the generically diagnostic basal imbricating plates in place, is chosen as the lectotype (see p. 119). It and the other discernible individuals, designated as paralectotypes (see p. 119), have their own catalogue numbers as follows: 
Lectotype USNM cat. no. 32407, Pilsbry 1907, pl. 5, fig.1, carina (C) and left carinolatus (CL) (left scutum (S) and tergum (T) missing); pl. 5, fig. 2, rostrum (R), right rostrolatus (RL) and basal imbricating plates $\left(r^{1}, r^{2}, r l\right.$, and $\left.r^{2}\right)$.

Paralectotype USNM cat. no. 284750, Pilsbry 1907, pl. 5, fig. 3, carina (C).

Paralectotype USNM cat. no. 284751, Pilsbry 1907, pl. 5, fig. 5, rostrum (R).

Paralectotype USNM cat. no. 284752, Pilsbry 1907, pl. 5, figs 4 (interior) and 7 (exterior), right scutum (S).

Paralectotype USNM cat. no. 284753, Pilsbry 1907, pl. 5, figs 6 (exterior) and 8 (interior), left tergum (T).

Table 2. Comparison of the number of articles of the six pairs of cirri and the caudal appendages. $a=$ anterior ramus, $p=$ posterior ramus, $r=$ right, $l=$ left.

Type of $C$. darwini darwini (USNM 32408, pers. obs.)

$$
\begin{aligned}
& \begin{array}{lllllll}
\text { a } & 12 & 17 & 21 & 24 & 21+26 & \text { c.a. }
\end{array} \\
& \text { - - - - - - } 13 \\
& \begin{array}{llllll}
\text { p } & 10 & 10 & 20 & 21 & 18+25
\end{array}
\end{aligned}
$$

Nilsson-Cantell's (1928) specimen: holotype of $C$. darwini cantelli

$$
\begin{array}{cccccccc}
\text { a } & 11 & 20 & 22 & 26 & 27 & 28 & \\
- & - & - & - & - & - & - & 12 \\
\text { p } & 13 & 22 & 24 & 27 & 28 & 29 &
\end{array}
$$

Hawaiian population

C6224B (1)

$$
\begin{array}{cccccccc}
\mathrm{a} & 10 & 16 & 20 & 24 & 23 & 24 & \\
- & - & - & - & - & - & - & 13 \\
\mathrm{p} & 12 & 20 & 21 & 23 & 24 & 23 &
\end{array}
$$

C6224B small $(r)$

$$
\begin{array}{cccccccc}
\text { a } & 6 & 7 & 10 & 13 & 15 & 17 & \\
- & - & - & - & - & - & - & 7 \\
\text { p } & 5 & 8 & 10 & 12 & 17 & 17 &
\end{array}
$$

C6665 (1)

$$
\begin{array}{cccccccc}
\text { a } & 9 & 15 & 19 & 23 & 24 & 25 & \\
- & - & - & - & - & - & - & 14 \\
\text { p } & 10 & 18 & 20 & 23 & 24+27 &
\end{array}
$$

Complemental male from Nilsson-Cantell's (1928) specimen (1): allotype (reg. no. 1997.715) of C. darwini cantelli (data from Hui and Moyse 1984)

$$
\begin{array}{cccccccc}
\text { a } & 4 & 5 & 6+11 & 10 & 12 & \\
- & - & - & - & - & - & - & 3 \\
\text { p } & 3 & 6 & 9 & 11 & 11 & 13 &
\end{array}
$$

Hawaiian complemental male (1)

$$
\begin{array}{cccccccc}
\mathrm{a} & 4 & 5 & 9 & 11 & 13 & 14 & \\
- & - & - & - & - & - & - & 9 \\
\mathrm{p} & 3 & 5 & 11 & 12 & 13 & 14 &
\end{array}
$$


Chionelasmus darwini cantelli subsp. nov.

Nilsson-Cantell 1928:446, figs 1 and 2; Hui and Moyse, 1984:91, fig. 1 (a complemental male attached to an adult hermaphrodite); Newman, 1987:24, fig. 4.

Diagnosis: Basal imbricating plates sr and $\mathrm{rl}^{\prime}$ generally appearing in third whorl rather than fourth and, concomitantly, no basal imbricating plate $\mathrm{c}^{3}$ overlapping $\mathrm{sc}$ present; articular furrow of scutum wide; articular ridge narrow and not prominent; articular ridge of tergum reaching to basitergal anglc; and basiscutal angle of tergum rounded rather than pointed, as compared to Chionelasmus darwini darwini.

Type: The hermaphrodite specimen [Natural History Museum, London, reg. no. 1928.5.23.84] collected from a telegraph cable in the western Indian Ocean at $526 \mathrm{~m}$, $15.3 \mathrm{~km}$ north and $64.4 \mathrm{~km}$ west of Port Mathurin, Rodrigues Island, and described as Chionelasmus darwini by Nilsson-Cantell (1928), has been selected as the holotype. The Madagascar specimens are named as paratypes. The dwarf male noted and dissected on nine slides by Hui and Moyse (1984) is named the allotype and given a new registration number, 1997.715 .

Etymology: Named in honor of the late Dr. C.A. Nilsson-Cantell (1893-1987), in appreciation of his excellent description and insights into the organization of Chionelasmus from the Indian Ocean.

Description: See Nilsson-Cantell (1928) and diagnosis given above.

\section{Acknowledgements}

I wish to thank Dr. Alain Crosnier for sending the specimens of Chionelasmus darwini from Madagascar to Scripps Institution of Oceanography (SIO) for study, and Dr. William A. Newman (SIO) for making them and the specimens from the Hawaiian Islands available and for kindly reading the manuscript and providing invaluable comments. I would like to thank Dr. Mark J. Grygier for providing nomenclatural assistance for this paper. This study was supported by a grant from the Japan Society for the Promotion of Science (JSPS) for six months' overseas research at Centers of Excellence Abroad. This study was also supported in part by a Grant-in-Aid for Scientific Research from the Japanese Ministry of Education, Science, Sports and Culture, project no. 06404001.

\section{References}

Buckeridge, J. S. 1997. A new coral inhabiting barnacle, Chionelasmus crosnieri sp. nov. (Cirripedia: Balanomorpha) from New Caledonia, Southwest Pacific. Zoosystema 20(2): 167-176

Foster, B. A. 1981. Cirripedes from ocean ridges north of New Zealand. New Zealand Journal of Zoology 8: 349-367.

Hui, E. and J. Moyse. 1984. Complemental males in the primitive balanomorph barnacle, Chionelasmus darwini. Journal of the Marine Biological Association of the United Kingdom 64: $91-97$.

Newman, W. $\Lambda$. 1987. Evolution of cirripedes and their major groups. pp. 3-42. I $m$ : Southward, A. 
J. (Ed.) Barnacle Biology. Crustacean Issues, vol. 5. Balkema, Rotterdam, 443 pp.

Nilsson-Cantell, C. A. 1928. The cirripede Chionelasmus (Pilsbry) and a discussion of its phylogeny. The Annals and Magazine of Natural History, Ser 10. 2(1): 445-455.

Pilsbry, H. A. 1907. Hawaiian Cirripedia. Bulletin of the Bureau of Fisheries 26: 181-190.

Pilsbry, H. A. 1911. Barnacles of Japan and Bering Sea. Bulletin of the Bureau of Fisheries 29: 59-84.

Yamaguchi, T. and Newman, W. A. 1990. A new and primitive barnacle (Cirripedia: Balanomorpha) from the North Fiji Basin abyssal hydrothermal field, and its evolutionary implications. Pacific Science 44(2): 135-155.

Yamaguchi, T. and Newman, W. A. 1997a. Eochionelasmus paquensis, new species (Cirripedia, Balanomorpha) from $17^{\circ} 25^{\prime} \mathrm{S}$, north of Easter Island: First record of hydrothermal sessile barnacle from the East Pacific Rise. Journal of Crustacean Biology 17(3): 488-496

Yamaguchi, T. and Newman, W. A. 1997b. The hydrothermal vent barnacles Eochionelasmus from the North Fiji, Lau, and Manus Basins, South-West Pacific. Zoosystema 19(4): 623-649 
